\title{
DIÁLOGOS ACADÊMICOS, INTERAÇÕES DIGITAIS
}

\section{ACADEMIC DIALOGUES, DIGITAL INTERACTIONS}

\author{
Luiza Helena Oliveira da SILVA ${ }^{1}$ \\ UFT - Universidade Federal do Tocantins
}

RESUMO: Este trabalho, inserido nas problemáticas da sociossemiótica, discute a aprendizagem ou a construção do saber sob a perspectiva do que essa abordagem teórica concebe como regime de ajustamento. A partir de uma problematização dos modos de interação entre sujeitos, mediados ou não por objetos, analisamos situações de interação que têm lugar no espaço virtual produzidas pela mobilização de dois gêneros digitais: o do fórum, considerando a participação de discentes em um curso de graduação presencial, e o chat, em duas diferentes sessões num evento acadêmico online. A análise aponta para a possibilidade de pensar o conhecimento numa perspectiva processual e dinâmica, com a instauração de interações mais simétricas, de fazer partilhado, em que o saber se elabora como efeito de um envolvimento conjunto. Por fim, pretende apontar para usos de ferramentas digitais com implicações para a prática pedagógica.

PALAVRAS-CHAVE: Semiótica discursiva; Regimes de interação; Presença; Chat.

ABSTRACT: This paper, inserted in the problematic of socio-semiotics, discusses learning or knowledge building from the perspective of what this theoretical approach conceives as adjustment scheme. From a problematization on the modes of interaction between subjects, mediated or not by objects, we analyze the interactions that take place in the virtual space produced by mobilizing two digital genres: of the forum, considering the participation of students in an presencial undergraduate course, and the "chat" in two different sessions at an online academic event. The analysis points to the possibility of thinking about knowledge in a procedural and dynamic perspective, with the introduction of more symmetrical interactions, with collaborative contruction, in what knowledge is produced with the effect of joint involvement. Finally, this paper intends to point to uses of digital tools with implications for pedagogical practice.

KEYWORDS: Discursive semiotics; Regimes of interaction; Presence; Chat.

Havia um muro alto entre nossas casas.

Difícil de mandar recado para ela.

Não havia e-mail.

O pai era uma onça

Manoel de Barros. A namorada.

\section{Introdução}

No poema "A namorada", o poeta Manoel de Barros (2001, p. 17) fala de um passado quando os meios de comunicação pareciam bastante rudimentares, pelo menos no que

1 Professora do Curso de Letras, do Programa de Pós-Graduação em Letras e do Mestrado Profissional em Letras (ProfLetras) da Universidade Federal do Tocantins. 
diz respeito às interlocuções amorosas. Como lemos nos versos iniciais citados como epígrafe, um primeiro problema era um muro a antepor-se entre os enamorados, acenando para a interdição. Não havia $e$-mail e a moça sempre tinha um pai atento às ameaças, "uma onça". O poeta ainda prossegue, discorrendo sobre outros entraves como um galho de goiabeira, que podia enganchar os bilhetes arremessados por pedras. Ultrapassado o "tempo do onça", expressão que cita no último verso e que serve para pontuar um passado indistinto, perdido, superado, qualificado como atrasado, adentramos num momento de muitas promessas em termos de tecnologias que favorecem amplamente diálogos entre gente de todo lugar. Diante de tais recursos, estaria em processo uma revolução em relação ao saber, mas que, a despeito de tudo, parece encontrar resistências, outras espécies de goiabeiras, quando se trata do universo escolar (SILVA e REIS, 2012). É sobre ações, usos e seus efeitos de que trata este trabalho, que problematiza interações digitais. Sem pretender fazer eco à euforia em torno da tecnologia, analisamos a apropriação de alguns ganhos tecnológicos para diálogos efetivos, sobretudo para aqueles que acenam na direção de implicações para a construção do saber. Alertamos ainda para o fato de que este texto organiza-se mais no plano das incertezas de indagações iniciais de quem se move em terreno instável e simultaneamente sedutor, do que no das conclusões produzidas, ao menos parcialmente, pelo rigor da prática de análise fundamentada na teoria semiótica no que ela já tem de solidamente edificado.

Há algum tempo, tendo em vista nosso trabalho num programa de pós-graduação que se orienta por problemáticas relativas ao ensino de língua e literatura, vimos buscando pensar as contribuições da semiótica para o ensino-aprendizagem, sobretudo na educação básica.

Como teoria da significação, obviamente, a semiótica tem muito a contribuir para as atividades de leitura na escola. Nesse sentido, serve como ferramenta aos professores em formação que têm diante de si a tarefa de levar os alunos a desenvolver sua competência de sujeitos leitores, não só no que diz respeito aos gêneros que tradicionalmente compareciam às aulas (contos, crônicas etc.), mas ainda para aqueles que vão mobilizar outras linguagens, como as notícias jornalísticas, os quadrinhos, os textos publicitários que trazem na sua configuração problemáticas de outras linguagens, como a visual, ou da ordem da melodia, como nas canções. Priorizando essas contribuições diretamente relacionadas à escolarização da leitura, encontramos trabalhos como os de Fiorin (2004), Teixeira (2011) e Gomes (2011). De um modo um tanto dessacralizante, por exemplo, em material de formação destinado a docentes da rede pública do Tocantins, o texto apresentado para tematizar a poesia é uma canção de Caetano Veloso e, assim, caberia aos docentes observar que a análise deveria ultrapassar a dimensão do puramente verbal, havendo outros elementos a serem levados em conta na leitura relativos à problemática do sincretismo de linguagens, além de considerar as especificidades que caracterizariam o texto da canção frente à poesia (REIS e SILVA, 2011). Fizemos ainda incursões relacionadas ao trato da literatura na escola, levando em conta a especificidade que deveria ser conferida ao texto na sua dimensão estésica e estética, valendonos, principalmente, das reflexões trazidas por Greimas em "Da Imperfeição", infelizmente até então mais sob o ângulo das "fraturas" (e, portanto, do acidente estético efêmero e imprevisível) do que no das "escapatórias", que mais de perto poderiam fornecer elementos para a lógica de uma aprendizagem inscrita na ordem do cotidiano (SILVA e MAGALHÃES, 2011; REIS e SILVA, 2011).

Considerando, contudo, questões de ordem prática que nos comovem, sobretudo, nos cursos de graduação presencial e semipresencial, iniciamos investigações ${ }^{2}$ que se relacionam à aprendizagem mediada por recursos digitais no que diz respeito à interação, instigados pelas

2Projeto de pesquisa "Interação e presença na esfera digital: investigações em semiótica discursiva sobre o uso de chats em contextos pedagógicos", cadastro AG4\#009/2012 (PROPESQ/UFT); bolsa CAPES 2013/2014.

Disponível em: http://seer.fclar.unesp.br/casa 
reflexões trazidas por Eric Landowski em "Passions sans nom" (2004, 2004a, 2005) e "Interacciones arriesgadas" (2009) ${ }^{3}$. Nessa direção, passamos a nos guiar por questões relacionadas à lógica do fazer sentido entre sujeitos, pensando as trocas entre alunos e professores, alunos e alunos, buscando elementos que visassem a compreender as dinâmicas relacionadas ao processo de aprendizagem e possibilidades de intervenção nas interações a fim de que se produzissem trocas mais qualitativas. Um dos trabalhos nessa direção foi apresentado na comunicação no GT de Semiótica da Anpoll (SILVA e REIS, 2013) e outro publicado no livro organizado por Lopes, Portella e Beividas (SILVA e REIS, 2012).

Alinhando-nos a semelhantes preocupações, aqui trataremos de interações digitais, diálogos acadêmicos travados em duas diferentes situações e nos valendo de gêneros distintos: a primeira entre alunos e professora num curso de licenciatura presencial; a segunda entre pares num evento acadêmico online.

Num primeiro momento, discorreremos brevemente acerca do que nos suscitam as reflexões de Landowski $(2004,2009)$ a respeito das interações, relacionando-as aos regimes da junção e da união. Em seguida, relacionaremos essas reflexões ao corpus, apresentando aí nossas conclusões.

\section{Formas de pensar as interações; formas de conceber a aprendizagem}

Em “Passions sans nom", Landowski (2004) problematiza o modo como até então a semiótica vinha tratando a questão da intersubjetividade. Inserida nos processos relativos ao nível narrativo, as interações entre sujeitos seriam, então, constituídas sempre pela mediação de objetos, pressupostas relações de conjunção e disjunção. A narrativa, nesse caso, se dá pela transformação da relação juntiva e todas as flutuações de estados da alma que afetam os sujeitos estariam a depender dessas operações de junção. Sob a ótica do regime de junção, os sujeitos não se encontrariam agindo jamais diretamente uns com e sobre os outros, mas sempre mediados pelos actantes objetos. Os programas narrativos daí decorrentes seriam o de doação e privação, pressupondo que, para a felicidade de um advenha o infortúnio do outro, restando a este a possível condição de invejoso ou rancoroso (LANDOWSKI, 2004).

Dando sequência a seu raciocínio crítico, o semioticista vai declarar que tal orientação teria como consequência, principalmente para os "analistas noviços", em suas "práticas escolares automatizadas", análises nas quais se conclui que um dado sujeito possa entrar em conjunção ou disjunção com objetos do tipo da liberdade ou da felicidade, como se remetessem a coisas passíveis de serem adquiridas de um "vendedor", o que denunciaria o caráter extremamente reducionista quanto às operações em processo.

Além disso, o teórico defende que o regime de junção se assenta sob uma ótica espacial, como se fosse uma mera justaposição, na qual o sujeito não entra efetivamente sequer em uma relação de natureza sensível com os objetos que lhe são atribuídos ou conquistados.

A esse modo de compreender a interação, conferida pela mediação dos objetos, Landowski adiciona um outro regime, que lhe seria diferente, mas complementar, e que vai se ocupar das relações de co-presença mútua, face a face, ou corpo a corpo, o que implica não apenas as relações sujeito-sujeito, como ainda outra forma de conceber a relação sujeitoobjeto.

Do ponto de vista dos objetos, estes não seriam então relacionados a uma ordem funcional previamente fixada, como estaria concebida na perspectiva do regime da junção.

3 Versão em espanhol de "Les interactions risquées" (LANDOWSKI, 2005).

Disponível em: http://seer.fclar.unesp.br/casa 
Como alteridade que se apresenta estesicamente ao sujeito, os objetos se dariam a conhecer/experimentar/apreender em razão de suas qualidades sensíveis, pressupondo sujeitos competentes para perceber/sentir os objetos em função das qualidades inerentes a sua materialidade.

Ainda sob esse raciocínio, os sujeitos não estariam constituídos definitivamente como uma totalidade racional, unívoca, autônoma, sempre a mesma, mas como inseridos numa ordem processual, sob o modo do devenir, como configuração sempre em movimento, em construção, a depender das relações que estabelecem com a alteridade (com outros sujeitos ou com objetos). Essa identidade se afasta, portanto, da atribuição de um papel já predefinido e fixado, acenando para a possibilidade de considerar a relação intersubjetiva como constitutiva da identidade dos sujeitos, postos em situação de co-presença. A identidade se move, assim, em função do estar no mundo, em função da experiência. A esse novo regime Landowski denomina "união". O regime de união se define, pois, como

modo de interação condicionada apenas pela co-presença dos actantes, tão somente pela possibilidade material de uma relação sensível entre eles. Recobre as configurações das mais diversas, mas todas tendo em comum o fato de se articular sobre a base de contatos estésicos a favor dos quais duas ou várias unidades inicialmente postas como distintas se ajustam entre si (unilateralmente ou reciprocamente) a constituir juntos, ou ao menos por um certo tempo, uma entidade complexa nova, uma totalidade inédita. (LANDOWSKI, 2004, p. 63) ${ }^{4}$.

Do ponto de vista da dimensão do sensível, os sentidos estão a depender da interação, de um aqui-agora com o corpo do outro que se lhe apresenta face a face. O sentido emerge no ato e a inteligibilidade envolverá, portanto, uma intersomaticidade e uma intersubjetividade.

Partimos dessa discussão para pensar o processo de aprendizagem, que implicaria como narrativa elementar considerar a transformação dos sujeitos. Sob a ótica da perspectiva juntiva, teríamos a passagem de um estado de disjunção com um dado saber para um estado posterior de conjunção com esse saber. O saber, assim, se apresentaria como uma totalidade que se dá a conhecer, apreender, como se não pusesse em ação maiores transformações do sujeito além da conferida pelo status da posse.

Esse modo de conceber a aprendizagem poderia ter lugar se pensado o saber sob uma orientação de natureza pragmática, como ocorreria diante da necessidade de dominar conteúdos listados para um concurso e efetivamente pouco significativos para o sujeito ou sob uma ótica acumulativa de caráter enciclopédico, preservando nos dois casos a relação com o que seria da ordem da exterioridade, que não implica ao que aprende um vir a ser distinto além do que lhe confere o caráter de sujeito da aquisição. Materializado na obtenção de um diploma, pode ser o passaporte para ingresso em função mais qualificada no mercado de trabalho e o saber que tal diploma representa poderia ser tão somente um vasto repertório apreendido por razões de ordem prática, alheia a outro tipo de transformações por parte daquele que se põe a aprender.

Tal concepção estaria ainda atualizada na perspectiva de que aprender se resume a saber repetir, dizer mais do mesmo, parafrasear, dizer o que, num dado contexto de ensino, é consensualmente tido como "certo", a justa resposta. Tal comportamento se justifica se pensado o saber não como algo processual, mas como um já dado e encontraria eco em 
práticas que, por falta de uma melhor denominação, qualificaríamos como tradicionais, remetendo a um ethos de escola sempre igual, lugar de acesso a um repositório de conhecimentos. Daí as ações decorrentes de decorar nomes, fórmulas, datas, conceitos, leis, verdades. Não caberiam então a reflexão, a crítica, a reconstrução, a ressignificação.

Um exemplo desse ethos incorporado como prática de ensino-aprendizagem, encontramos a seguir. Numa atividade proposta a acadêmicos matriculados no primeiro semestre de uma licenciatura em Letras, cursando a disciplina denominada "Introdução aos Estudos Linguísticos", a professora ${ }^{5}$ propõe que os alunos discutam no fórum construído na plataforma virtual Moodle a seguinte questão: "Comente a crítica feita por Leroy acerca do caráter apriorístico das reflexões linguísticas no século XVIII”:

O que se pode entender pela crítica de Leroy, e que até então as línguas não tinha interferência umas sobre as outras, e após o suposto caráter apriorístico das reflexões linguísticas houve mudanças, talvez por isso tenhamos tantas palavras da língua inglesa no nosso vocabulário do dia a dia. (Acadêmico $1)^{6}$.

O que se entende - pela crítica feita por Leroy a respeito do caráter "apriorístico" das reflexões linguísticas e que passou a fazer um misto das línguas existentes, passando-se assim a usá-las em seu cotidiano, como parte de seu dialeto. Um exemplo disso são as várias palavras em inglês muito comum em nosso português as famílias de língua, não conseguiram ser catalogadas ao conjunto das línguas do mundo. (Acadêmico 2).

Deixando transparecer não terem compreendido o que significa o adjetivo "apriorístico", ou suas implicações para as investigações dos estudos linguísticos relativas ao período estudado, as postagens reduzem-se à repetição, na crença de que o primeiro a responder pudesse ter a resposta "correta". Se a noção do gênero fórum incorpora a noção de diálogo e partilha, o diálogo estaria aqui de todo ausente e a partilha consistiria tão somente em dar eco a enunciados que não fazem qualquer sentido. Seria a justa resposta, mas não resultado de uma reflexão mais engajada. A relação com o dizer do outro (Acadêmico 1) é tão somente de reprodução, sem questionamentos, sem acréscimos e alterações além do necessário a uma paráfrase que vai tornar ainda mais obscuro o texto produzido (Acadêmico 2).

Frustrada a hipótese de uma construção mais reflexiva e significativa, a atividade, contudo, serviu à docente para conferir a dimensão das dificuldades a sua frente: a necessidade de agir sobre um ethos de escola já cristalizado pela experiência dos sujeitos e pouco produtivo no ambiente acadêmico, as dificuldades denunciadas no que diz respeito à compreensão sobre as questões problematizadas nas aulas, a urgência de produzir outras situações em que a reflexão estivesse à frente da mera reduplicação do dizer alheio.

Para justificar que o saber não se resume a uma relação de junção, Landowski traz o exemplo de Mozart:

5 Os dados analisados foram gerados durante uma de nossas disciplinas no curso de graduação. O fórum em questão foi o primeiro que propusemos e contou com uma participação pouco expressiva. Os exemplos analisados são representativos dos procedimentos predominantemente adotados pelos acadêmicos na atividade. 6 Mantivemos a redação dos acadêmicos sem alterações que visassem à correção gramatical. Acreditamos que o próprio truncamento dos textos pode ser indicador do alheamento em relação ao assunto sobre o qual discorrem.

Disponível em: http://seer.fclar.unesp.br/casa 


\begin{abstract}
Não se diz, por exemplo, que, ouvindo tocar, e ouvindo Haydn, o pequeno Mozart tornou-se Mozart? Se este for o caso, a partitura escrita pelo primeiro - o mestre - não satisfaz a função de um simples objeto valor objeto de conhecimento ou de acordo - de que o segundo, o estudante, quereria se apropriar, do qual gostaria de estar conjunto para preencher uma falta, ou ainda com a qual tinha sonhado, como dizem apressadamente, fundir-se, para seu prazer. Ao contrário, o dito objeto, o texto, a coisa musical intervém na situação como um interactante no sentido pleno do termo, como um verdadeiro co-sujeito capaz, por seu contato intencional e dinâmico, de levar o jovem músico a experimentar através desse contato uma forma de apreensão, de torná-lo de uma vez por todas um outro que não era, de transformar suas potencialidades (seus dons), de uma maneira efetiva e nova de estar no mundo, capaz de relevar a ele mesmo e, de fato, de contribuir de forma decisiva para fazer nascer o futuro compositor. (LANDOWSKI, 2004, p. 71)
\end{abstract}

Partindo do exemplo de Mozart que nos parece irrefutável, seríamos convidados a pensar o saber sob diferente aspecto, inserido sob um outro regime, mais dinâmico que o da junção, em que o que se apreende pode ser transformado, na medida em que aquele que apreende também se transforma. É certo que, no caso da música, trata-se de uma relação propriamente estésica, a atuar sobre os sentidos e a percepção, mobilizando o sujeito além de um saber propriamente intelectual. Mas nos revela que a aprendizagem ultrapassa a dimensão da repetição de uma performance prevista e predeterminada.

Mais uma vez remetendo a Landowski (2009), a repetição, o mais do mesmo, a previsibilidade, a ausência de riscos dada pela cristalização de práticas e ideias, poderia apontar, no âmbito das práticas de interação na sala de aula, para o que esse teórico intitula como regime de programação e que tem como consequência a dessemantização. A quotidianidade das aulas, na repetição de seus rituais de abrir e fechar de livros, sucessivas e idênticas orientações para ler e responder às questões anteriormente definidas pelo autor do livro didático, por exemplo, podem fazer da atividade de estudar um verdadeiro martírio, e um possível poema (objeto estético, portanto), que porventura por lá compareça proposto para a leitura, pode tornar-se abjeto, rejeitado pelo estudante exaurido e enfastiado.

Do ponto de vista dos quatro regimes de interação preconizados por Landowski (2009), podemos conceber um continuum que parte do máximo de previsibilidade conferido pelo regime da programação à total imprevisibilidade atribuída ao regime do acidente, espécie de fratura instaurada pelo inesperado. Ainda levando em conta uma imagem de escola, o acidente poderia ser atribuído a projetos muito bem sucedidos, com seus pontos de culminância festivos relativos à sua fase de conclusão, mas que, por sua natureza acidental e descontínua, não guardam maiores consequências para as práticas escolares. Assim, finalizado o referido projeto, tudo voltaria à santa paz dos dias insuportavelmente iguais.

Entre o enfado da repetição e a natureza imprevisível do irrepetível, encontram-se os regimes da manipulação e do ajustamento. No caso da primeira, a interação é da ordem da junção, a respeito do que discorremos até aqui com suas implicações. Em relação ao segundo e a dinamicidade que comporta é que nos interessa analisar trocas entre acadêmicos num evento online.

Sob o regime do ajustamento, instaurar-se-iam as noções de reciprocidade e intersomaticidade conferidas pela co-presença dos sujeitos. Nesse sentido, como conceber trocas que têm lugar no espaço virtual? 


\section{Entre pares}

Nossas reflexões se voltam aqui para análises de interações online mediante o recurso do chat no "X Encontro Virtual de Documentação em Sofware Livre" (EVIDOSOL) e "VII Congresso Internacional de Linguagens e Tecnologia online" (CILTEC) (http://evidosol.textolivre.org/), realizados em junho de 2013. Os eventos que ocorreram simultaneamente previam interações síncronas (como nos chats) e assíncronas (nos fóruns e blogs). Num primeiro recorte, selecionamos aleatoriamente uma sessão de chat, do dia 3 de junho, na qual foram apresentadas e discutidas cinco comunicações, todas problematizando questões relativas ao digital. Para este trabalho, nossa atenção se detém mais precisamente sobre duas dessas comunicações, a primeira discorrendo sobre o lançamento do livro "Recursos Educacionais Abertos: práticas colaborativas e políticas públicas" e o segundo apresentando reflexões fundamentadas na Análise do Discurso francesa e abordando "a organização e circulação de dizeres e arquivos no Twitter". Esse segundo recorte se orienta pelas aproximações e distinções que identificamos na configuração dessas trocas interativas e que poderiam fornecer elementos para pensar sobre as implicações do digital para a produção de conhecimento; a primeira com 67 minutos de duração (que designaremos a partir de agora sala 1); a segunda (sala 2) totalizando 40 minutos.

Analisando o diálogo pressuposto por uma carta, Landowski (2002) vai apontando para elementos que remetem a efeitos de presença dos parceiros, como uma "autêntica 'presentificação' recíproca" (2002, p. 167). Não coincidentes espacial e temporalmente, a carta simula o encontro intersubjetivo, e o outro, o ausente, vai sendo construído como "instância presentificável" (2002, p. 166). Pressupondo uma relação de junção anterior, as cartas que remetem aos sentidos do afeto teriam como referente a falta, a ausência, a disjunção, como se não houvesse nada mais a dizer além do lamento da separação. Ao escrever, o outro é então convocado, presentificado, intensificando-se os sentimentos da falta pela intensificação dos sentimentos da presença.

No evento em questão, de natureza online, uma das questões que emergem é justamente a da distância "real" que separa os sujeitos e que não guardam para si a vivência de um estado anterior conjunto. Não há afetos que orientem a comunhão, mas interesses relativos ao conhecimento acadêmico que seriam então publicizados e, na medida do possível, enriquecidos pelo empenho dos presentes para aprofundamento dos temas. A distância "real" é, assim, obliterada pelos recursos digitais que, contudo, escapando ao controle dos parceiros da interação, podem sofrer quedas, demoras, produzindo interdições. Antecipando-se a problemas dessa natureza, numa das páginas do EVIDOSOL, como orientações para os participantes, há um tutorial, e, diante de possíveis contratempos, a apresentação de uma justificativa: "Se houver algum problema de conexão (existem milhares de quilômetros de fios entre nós), tente entrar pelo outro chat" (<http://evidosol.textolivre.org/index.php?option=com_content\&view=article\&id=59\&Itemid $=83>$ ), ao que se seguem links que garantiriam a entrada no evento. A esses milhares de quilômetros de fios invisíveis a conectar os sujeitos estariam outros fios que se dão a conhecer pelo texto que se constrói coletivamente.

Nos chats, a co-presença se dá na instância do virtual, num "aqui" representado por uma sala que toma corpo pela coincidência temporal das postagens. A passagem do tempo vai sendo explicitada a cada novo comentário e a identificação dos co-enunciadores se dá pelos nicknames, nomeação que muitas vezes serve tão somente aos propósitos de uma situação de interação específica travada no espaço virtual, sem reportar necessariamente à identificação 
dos sujeitos. Como serve aos propósitos de uma comunicação acadêmica, organiza-se como nos eventos presenciais: o que comunicará o trabalho é apresentado pelo moderador, que cumprimenta os "presentes" e informa sobre as regras relativas à exposição e a participação dos demais.

O que vai denunciar, então, a presença, são as postagens, sempre acompanhadas da identificação dos sujeitos pelos respectivos nicknames, o momento preciso em que tal se deu (horas e minutos), a ocorrência da debreagem actancial enunciativa e a nomeação daquele a quem o dizer se destina: a "fala" pode direcionar-se para todos, sem evidenciar distinções, ou remeter a alguém em especial, expressamente convocado, como nos exemplos abaixo (sala 1):

[18:45] <milenahygino> Concordo, <anepatti>

[18:46] <Bianca_> Super, Pablo!!! ${ }^{8}$

Na sala 1, num dado momento dos debates, um dos internautas responsáveis pela apresentação, mas "ausente", como informado pelo moderador no início da sessão, comparece, para declarar que acompanha a sessão, embora "em silêncio":

[18:51] <nelsonpreto> (grato. Estou aqui mas no meio de outra atividade, perdão... acompanho em silêncio. estou no Rio, dando uma aula na Bahia e vendo vocês aqui...)

O "aqui", assim, é esse que se constrói num texto em processo, materializado na tela em movimento, que ganha novas configurações a cada intervenção. O efeito de estar "aqui", lugar compartilhado da interação, é o que se produz quando se fala (escreve), intervindo, ainda que para declarar as distâncias que situam os co-enunciadores em esferas geográficas efetivamente distintas. Na postagem de <neolsonpreto>, vemos, então, a declarada dispersão desse sujeito, multiplicando-se entre Rio, Bahia e o "aqui" da sessão. Os efeitos de ausência e presença estão, assim, a depender das postagens, que dão a conhecer quem está no "aqui" construído pelo chat.

Seguindo as orientações do gênero e das práticas correspondentes, os apresentadores têm, na sala 1, 40 minutos para exposição; na sala 2, 20 minutos. Essa diferença substancial de tempo incide diretamente sobre a qualidade das comunicações. Na sala 2, com tempo bem menor, as postagens mal possibilitam que sejam apresentados o problema da pesquisa, os objetivos do trabalho, trazendo em linhas muito gerais o modo como a análise do discurso, teoria que subsidia a pesquisa apresentada, colabora para as reflexões sobre a problemática do arquivo. Com isso, apenas a partir do momento destinado aos questionamentos é que se podem antever as razões para a menção ao Egito, que aparece no título da comunicação e a respeito do qual nada fora anteriormente dito. Não houve, portanto, tempo para a apresentação da análise, muito menos para as conclusões. Resta, assim, à apresentadora <viviannlee> remeter ao artigo publicado nos anais do evento.

[20:35] <viviannlee> Algumas das análises podem ser encontradas no artigo do congresso.

[20:35] < viviannlee> Obrigada!

[20:35] <CarlosCastro> Vivian, você tem mais alguma questão ou podemos abrir para perguntas?

8 Transcrevemos fragmentos dos chats sem alterações referentes a uma correção gramatical.

Disponível em: http://seer.fclar.unesp.br/casa 
[20:36] < viviannlee> Pode abrir para perguntas

[20:36] <CarlosCastro> Agradecemos a apresentação de Vivian Lemes Moreira. Estamos abertos às questões dos ouvintes/leitores.

[20:36] <hmlins> Olá Vivian. De fato, considero que o discurso materializado na web (nesse caso, via microblog) mostra a dinamicidade da linguagem, na perspectiva sócio-interacionista...

[20:37] <hmlins> interessantes suas observações.

[20:38] <Pablo_> a linguagem é por natureza interacionista, essa interação ganhou força com a internet?

[20:38] <dilma> Boa noite a todos e a vc vivian gostaria de perguntar de modo prático como se dá a materialidade discursiva na web?

[20:38] <viviannlee> hmlins atualmente presenciamos muito além da interação na web, a partir da convergência midiática. A comunicação interativa evidenciada cada vez mais através das ferramentas das rede sociais na web, passa a influenciar (in)diretamente em diversos outros processos, práticas e discursos na sociedade, quais seja, na sociedade on-line e na off-line.

[20:39] <sandraf> Vivian, sei que está no artigo , mas você poderia nos adiantar por que o Egito?

[20:39] <dilma> Como o um leitor normal pode perceber a análise do discurso na Web?

[20:39] <Marcus_> Vivian, vc poderia resumir um pouco os efeitos de sua análise na pesquisa que $\mathrm{vc}$ realizou?

Como se pode ver, um dos participantes da sessão solicita esclarecimentos sobre a opção pelo "Egito", o que vai ser explicado brevemente mais adiante. Mas há outras questões imediatamente propostas e simultâneas, como a marcação temporal explicita. Já que não há como "ouvir", senão depois de já postado o texto, os parceiros dessa interação podem escrever juntos, perguntar ao mesmo tempo, do que decorre que, inevitavelmente, nesse aparente caos, algumas questões sejam ignoradas ou ainda só possam ser muito superficialmente consideradas, como fica visível nessa intervenção abaixo, na sala 1:

[18:36] <Pablo_> sou leigo no assunto, por isso me explica o q é uma obra copyright, e sua tradução

No caso do exemplo acima, <Pablo> não obtém esclarecimentos sobre sua questão, mas continua participando, denunciando esforço de quem acaba por aproximar-se de uma das problemáticas centrais relativas ao tema da sessão. A aceleração e a fragmentação vão, desse modo, constituindo um modo específico de negociação e partilha de sentidos e saberes, o do chat, que não substitui um outro tempo, o da leitura do artigo, sob um outro ritmo, construindo um outro modo de interação, como a apresentadora <viviannlee> sinaliza.

A necessidade de digitar o texto implica um tempo maior do que seria numa apresentação oral, e o texto que vai se configurando não remete a algo anteriormente pronto, mas que vai sendo construído no chat, dando mostras de se submeter à lógica da interação. Lendo o que resultou do chat, podemos identificar semelhantes procedimentos de uma comunicação face a face, com a saudação inicial pelo moderador e por outros participantes ("boa noite"), a apresentação de quem terá inicialmente a palavra, a explicitação das regras, o fechamento, os agradecimentos finais, o informe sobre o intervalo de 15 minutos, características que reiteram o efeito de co-presença/face a face dos sujeitos. 
Elementos que caracterizam mais de perto a oralidade são mobilizados, como a utilização do termo "bom", introduzindo o que corresponderia a um turno conversacional. Como a escrita deve ser acelerada, sem possibilidade de revisões mais atentas, estão mais presentes erros de digitação, com trocas de letras, ou sua supressão, da mesma forma que não há muito rigor quanto ao uso de maiúsculas. O gênero, portanto, impõe seu ritmo, configurando uma prática peculiar de escrita e interação.

Na sala 1, essa configuração se repete, mas tem como elemento de singularidade que algumas poucas intervenções se dão em meio à fala da apresentadora da comunicação. As postagens também são mais curtas, conferindo efeito de mais agilidade, representando menos "esperas" por parte dos demais participantes. Não há também uma marcação precisa definindo o momento destinado às intervenções como expresso na sala 2. As intervenções vão, assim, se tornando mais frequentes, já interferindo no tempo destinado à apresentação inicial e diluindo gradativamente a centralidade do apresentador ao longo da sessão.

Por representar uma temática que parece ser de conhecimento mais partilhado pelo grupo (recursos educacionais abertos - REA), somam-se contribuições e menos solicitações de esclarecimentos, como ocorrera na sala 2, o que também serve para produzir um multidirecionamento das postagens: estas não se dirigem sempre apenas ao apresentador da comunicação, mas também a diferentes sujeitos ali presentificados.

[18:39] <Bianca_> tudo que for pago com dinheiro do município é REA.

[18:39] <jaiza> É verdade! Quando usamos um software proprietário para produzir um texto e disponibilizá-lo na rede não poderemos dizer que aquele documento é nosso. O proprietário do software pode negar-nos o documento, o acesso.

[18:39] <caroleao> tem muito a ver com o trabalho anterior e essa ideia pode realmente aproximar os alunos do uso de tecnologias na aprendizagem e criar um ambiente em que outras pessoas possam interagir

A sala, então, se traduz num diálogo mais simétrico que na sala 2 , e, numa das postagens, a própria apresentadora levanta uma questão para um dos presentes. Este já se pronunciara em muitos momentos e, como podemos constatar no fragmento abaixo, também denuncia dificuldade em responder ao problema, que se trata de uma dúvida também por ele partilhada:

[18:49] <jaiza> Professores autores, estimularam seus alunos a serem autores também.

[18:49] <anepatti> O ganho cai na roda do social

[18:49] <anepatti> Circular a produção de conhecimentos

[18:49] <Bianca_> Perfeito, Ane.

[18:49] <anepatti> Que bonito iss

[18:49] <Bianca_> E gonaloabio, tenho dúvidas sobre os repositórios...

[18:49] <Bianca_> Dá pra publicar em qualquer lugar, em licença livre e formato aberto.

[18:49] <gonzaloabio> eu também

Nessa perspectiva de construção de conhecimento, o saber, portanto, não se acha pronto, irredutível, concentrado num sujeito a quem todas as atenções se destinam, mas vai se fazendo por aproximações, trocas, intervenções, ressignificando na relação de interação. 
Construído da efemeridade da instância única de um aqui-agora irrepetível, o saber se alarga e se complexifica, a depender do dizer do outro, que confirma, soma e problematiza o que vai sendo conjuntamente exposto. Acelerada a forma de interação, o resultado pode apontar para lacunas, mal entendidos, aberturas que ficam a solicitar esclarecimentos e fechamentos, mas que acabam por sinalizar também para o possível diante das novas tecnologias de interação e para a própria processualidade e inacabamento do saber.

\section{Considerações finais}

Do ponto de vista da organização precisa do encontro, das formas previstas de interação (chat, blog, fórum), das regras para participação, do tempo destinado a apresentações e intervenções, podemos pensar inicialmente no regime de programação. Mas, ainda que como paráfrase ou fichamento de produções já publicadas, devidamente divulgadas e amplamente reconhecidas, o arranjo que se apresenta traz aí uma leitura particular, um resultado que possa produzir estranhezas, atritos, ressignificações, isto é, não há a previsibilidade de uma programação, ainda que uma espécie de ritual comande a estruturação dessa modalidade de encontro.

Nesse aspecto, podemos pensar no regime de manipulação, no qual o apresentador da comunicação visa a garantir a adesão dos demais, para que comunguem com ele do que podem ser tão somente precárias certezas. A obediência às regras do texto acadêmico, a sua configuração textual, a fundamentação teórica, o rigor quanto à linguagem e procedimento metodológicos etc. visam a garantir essa adesão, ou, ao menos, a evitar riscos de uma crítica severa. A depender dos sujeitos que interagem, contudo, podemos ainda pensar em ajustamentos que não se qualificam como tal pela dimensão estésica em relação ao que o outro traz apenas de elemento indicial (o nome, por exemplo, mera evocação do outro), mas pela negociação frente ao que se apresenta como saber em processo. As relações não seriam, assim, relativas à corporeidade do outro (como temos diante de um livro, seu cheiro, seu formato, sua capa, o modo de impressão, o papel ou como temos num evento presencial em que contam não apenas as cumplicidades teóricas, mas a proximidade do outro, como ainda as relações de afeto). Nesse caso, o ajustamento se daria pelo envolvimento no que se apresenta como objeto de discussão, portanto, pela relação com a dimensão (i)material do conhecimento.

Podemos discordar, dizendo que aqui também as relações entre os sujeitos se dão pela mediação do objeto, reiterando o raciocínio previsto pelo regime da junção. Mas o que se modifica é a natureza mesmo do objeto que se interpõe e motiva a comunhão dos sujeitos. Não se trata de algo que se possa passar de mão em mão, nem pode ser concebido como algo definitivo, a tornar sábio de uma vez por todas seu detentor, embora as práticas de repetição acrítica apontem para isso.

O que temos, enfim, é a experiência de um contato de ordem cognitiva, que, embora extremamente acelerado, pode contribuir para a reflexão dos sujeitos. Remete ao modo como hoje produzimos sentido e conhecimento, figurativizando o que podem ser algumas das nossas escapatórias no exercício de dar sentido ao mundo.

\section{REFERÊNCIAS}

BARROS, M. de. Tratado geral das grandezas do ínfimo. Rio de Janeiro: Record, 2001. FIORIN, J. L. Linguística e pedagogia da leitura. Belo Horizonte, Scripta, 2004, v. 7, n. 14, p. 107-117. 
GOMES, R. S. Semiótica e ensino: modalização e leitura do texto. In: RAMOS, D. V.; ANDRADE, K. dos S.; PINHO, M. J. de (Orgs.). Ensino de língua e literatura: reflexões e perspectivas interdisciplinares. Campinas, SP: Mercado de Letras, 2011.

GREIMAS, A. J. Da imperfeição. São Paulo: Hacker, 2002.

LANDOWSKI, E. Presenças do outro: ensaios de sociossemiótica. São Paulo: Perspectiva, 2002.

Passions sans nom: essais de socio-sémiotique III. Paris: PUF, 2004.

Modos de presença do visível. In: OLIVEIRA, A. C.(Org.). Semiótica plástica. São Paulo: Hacker, 2004a.

. Aquém ou além das estratégias, a presença contagiosa. São Paulo: CPS, 2005.

Interacciones arriesgadas. Lima: Universidad de Lima, Fondo, 2009.

Les interactions risquées. Limoges: Pulim, 2005.

REIS, N. V.; SILVA, L. H. O. Lendo poesia na escola: análise de orientações para a leitura do gênero poema em material de formação continuada. In: SILVA, N. L.; ALMEIDA, V. (Org.). Reflexões sobre ensino e formação de professores: diálogos entre Educação Superior e Básica. 1. ed. Palmas: Nagô, 2011, v. 1, p. 87-100.

SILVA, L. H. O; REIS, N. V. Diálogos virtuais e regimes de sentido: análise semiótica de chats em contexto do ensino. No prelo, 2014.

SILVA, L. H. O.; REIS, N. V. A escolarização do gênero chat: reflexões na perspectiva da semiótica discursiva. In: Anais do II SIELP - Simpósio Internacional de Ensino da Língua Portuguesa. Uberlândia: Editora da Universidade Federal de Uberlândia, 2012.

SILVA, L. H. O.; MAGALHÃES, H. G. D. Do reino da beleza à república do gosto: questões para o letramento literário. In: RAMOS, D. V.; ANDRADE, K. dos S.; PINHO, M. J. de (Orgs.). Ensino de língua e literatura: reflexões e perspectivas interdisciplinares. Campinas, SP: Mercado de Letras, 2011, p. 81-92.

TEIXEIRA, L. Leitura e interpretação de textos: contribuições da teoria semiótica. In: RAMOS, D. V.; ANDRADE, K. dos S.; PINHO, M. J. de (Orgs.). Ensino de língua e literatura: reflexões e perspectivas interdisciplinares. Campinas, SP: Mercado de Letras, 2011, p. 139-153. 